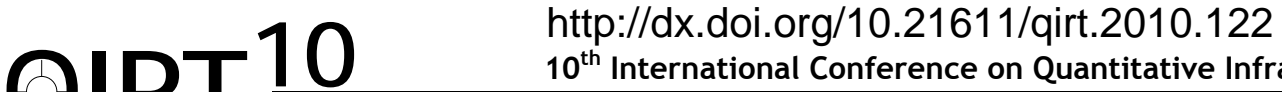 \\ $10^{\text {th }}$ International Conference on Quantitative InfraRed Thermography \\ July 27-30, 2010, Québec (Canada)
}

\section{Heat transfer investigation in an hypersonic boundary layer}

\author{
by P. Schreivogel*, G. Paniagua*, H. Bottini*, D. Masutti*, O. Chazot*, J .P. Solano**
}

*Turbomachinery and Propulsion Dept., von Karman Institute, Belgium 1640, paniagua@vki.ac.be

**Dept. Ingenieria Térmica y de Fluidos, Universidad Politécnica de Cartagena, Spain 30202

\begin{abstract}
This paper presents an experimental study on transition in a hypersonic flat plate. In particular, the compressible boundary-layer flow over the intake of a scramjet engine is considered. The work was carried out in the frame of the EUfunded, ESA/ESTEC-lead LAPCAT2.

An existing flat plate layout was complemented with high-frequency temperature instrumentation and a resistive heating. Thus the transition process and wall temperature influences can be studied. Thin-film as well as infrared measurements were carried out on the flat plate surface. The development of the boundary layer on the clean surface and in the wake of roughness, which was applied close to the leading edge, was investigated. Fig.1 presents Stanton number distributions downstream of distributed ramps and sand. Furthermore, the influence of an increased wall temperature were tested. The test were carried out at a unit Reynolds number of $25106 \mathrm{~m}$. The comparison to the thermography and the consistency of the thin-film measurements showed the applicability of the technique in the harsh hypersonic environment. Temperature fluctuations up to a frequency of $100 \mathrm{kHz}$ could be measured.

The steady as well as the transient heat flux results suggest a dominant influence of free-stream disturbances. Roughness and heating did not significantly change the assumed transition location at about 55\% of the plate length. Correlated signals which were found at the transitional region suggest the appearance of turbulent spots. A comparison of existing free-stream hot-wire measurements and the thin-film signal spectra showed similar qualitative characteristics. It is assumed that the boundary-layer adapts to the external disturbances in the observed frequency band.
\end{abstract}

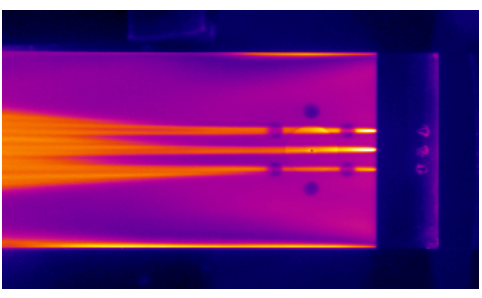

Ramps, $k=0.9 \mathrm{~mm}$

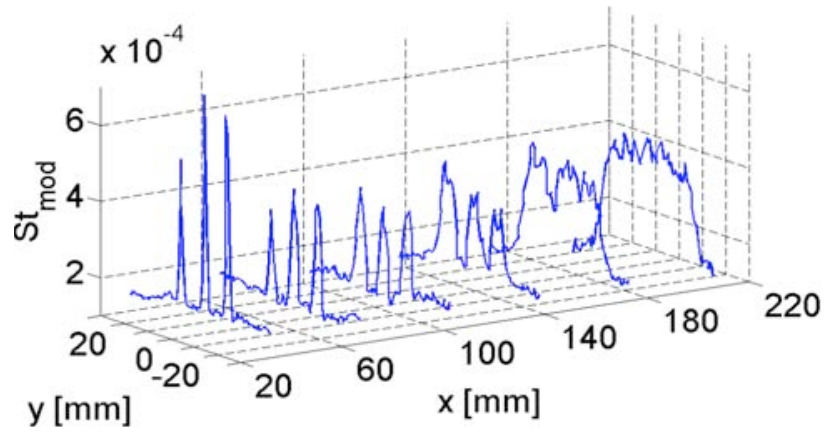

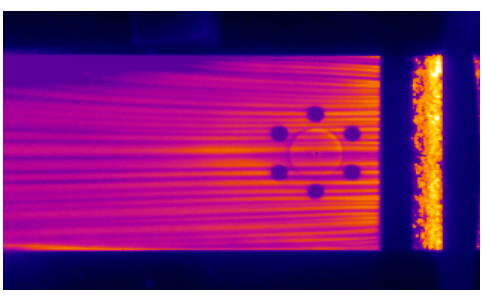

Sand, $(420 \ldots 590) \mu \mathrm{m}$

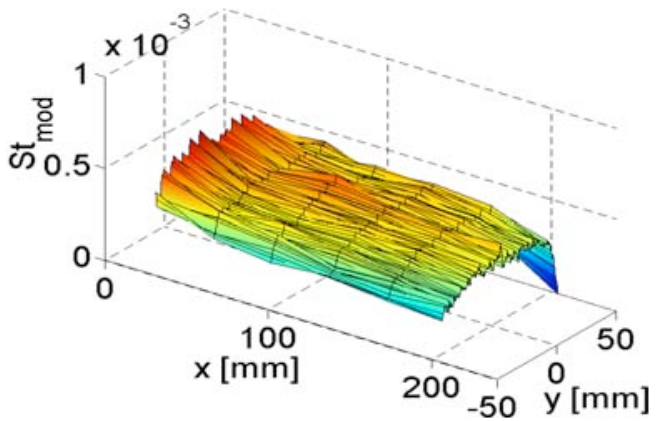

Fig. 1. Steady heat flux measured with infrared thermography in the presence of ramps and sand 